\title{
Editorial
}

\section{Flipped classroom: Revisit, adapt and adopt}

\author{
Ajit Dabholkar ${ }^{1, *}$ \\ ${ }^{1}$ School of Physiotherapy, D. Y. Patil University, Nerul, Maharashtra, India
}

\section{A R T I C L E I N F O}

Article history:

Received 15-12-2021

Accepted 25-12-2021

Available online 13-01-2022
This is an Open Access (OA) journal, and articles are distributed under the terms of the Creative Commons Attribution-NonCommercial-ShareAlike 4.0 License, which allows others to remix, tweak, and build upon the work non-commercially, as long as appropriate credit is given and the new creations are licensed under the identical terms.

For reprints contact: reprint@ipinnovative.com
Technology based approaches have become a greater priority during the COVID 19 pandemic. This has led in changing the educational landscape to blended learning. This shift has led educators to adapt strategies to develop student engagement, foster critical thinking and improve learning abilities and active participation. One such approach is "Flipped Classroom."

The 'Flipped Classroom' refers to an approach in teaching where the traditional class room time and selfstudy activities are reversed or 'flipped'. In practice activities there can be many forms, but mostly involve students preparing for class by watching a pre-recorded lecture/video based instruction or undertaking assigned reading tasks and activities, followed by the 'lecture' time being used for interactive classroom session which engages the students through problem-solving and other activities with the teacher. As such the role of the teacher shifts from being the 'sage on the stage' to the 'guide on the side

A systematic review published by HEW and LO in 2018, suggests that the flipped classroom approach in health professions education yields a significant improvement in student learning compared with traditional teaching method. ${ }^{1}$ Despite the evidence supporting the use of the flipped classroom model has yet to be widely adopted by varied health care professional educators.

\footnotetext{
* Corresponding author.

E-mail address: ajitdabholkar1211@gmail.com (A. Dabholkar).
}

\section{Revisiting Flipped Classroom Approach}

Firstly, it may be useful to provide learners with the rationale and benefits for using the flipped classroom in a medical education setting. For the trainers, Training should be provided to educators with worked examples of how the flipped classroom can be applied within their own area of expertise.

Conducting needs assessments, determining content and learning outcomes, and selecting appropriate educational and assessment methods. ${ }^{2}$ Also need to integrate new topics, methods, and people onto a course, or solve other existing challenge.

Educators require time to learn and incorporate new technologies, and devise effective ways to present course material and utilize the flipped classroom to tailor education to the learners' needs. A virtual learning environment (VLE) gives an opportunity to support flexible and learner centred approach leading to active learning, this enables a great interaction amongst the educator and learner getting real time feedback and have an effective problems solving session and determine gaps in student comprehension. An educator must select a topic for flipped classroom that experiences poor student engagement, or a module that needs to facilitate increased learner critical thinking.

Flipped classroom techniques can be incorporated around single topics or modules; indeed there is evidence to suggest that students prefer courses that are divided into both traditional and flipped classroom portions. In one 
study, indicated that a balance of $30 \%$ flipped classroom and $70 \%$ traditional classroom represented the optimum balance. $^{3}$

Facilitators may also consider limiting total length of all combined video segments to about $20 \mathrm{~min}$. Support for this comes from several non health professions educationrelated flipped classroom studies ${ }^{4}$ which few studies reported that most students spent up to 20-25 min on viewing pre-class video.

Start your class with quizzes at the beginning which may help students recall the knowledge learned prior to the class. Prior knowledge has long been considered an important factor influencing learning. The retrieval of information from memory makes the path to that information in memory stronger; this consequently enables the information to be more easily retrieved by the learner on the next occasion. Having quizzes at the beginning of class also allows an educator to identify students' possible misconceptions of the pre-class materials. Students' misconceptions can prevent further learning if not addressed. Based on student performance, educators can provide remedial action if necessary such as reviewing the pre-class video lectures or making adjustments to the in-class teaching plans to specifically address the students' misconceptions. Lesson can also serve as a strong motivator for students to watch the pre-class video lectures. This finding thus implies that instructors use quizzes as a regular part of the inclass activities to assess students' mastery of the pre-class learning material.

\section{Adapt and Adopt-two Sides of the Coin}

Flipped classroom are proven to be increase student engagement, thereby enhancing their learning outcomes and improving motivation and attitudes. Authors believed that for the more positive student perception, as well as the greater effect of flipped classroom over traditional classroom, is that having unrestricted access to prerecorded video lectures before class enables students to learn anywhere and at any time, at their own pace. ${ }^{5}$ Students can also watch the videos multiple times to better understand a particular topic. ${ }^{6}$ Another view point is availability of more in-class active learning time to help increase students' understanding of the subject in depth. Many of the in-class activities such as smallgroup discussion promoted students' interactions with their peers. ${ }^{7}$ Facilitators/instructors also felt they had greater opportunity to provide more feedback during inclass sessions. ${ }^{8}$ There were also greater opportunities for students to apply their knowledge in flipped classes through experiential learning; team based learning, problem based learning, case based learning, collaborative learning and self determination. All these participatory skills make a student a reflective and flexible thinker.

A study demonstrates that while engagement with flipped classroom is influenced by a complex interaction of factors (including variation in learning and teaching styles of individuals as well as the feasibility and flexibility of overall course design. The success of the flipped model is primary underpinned by managing student's expectation. A growing body of literature also highlights many complexities of flipping and demonstrates that there are varied outcomes. "Not all flipped classroom are created equal." The learner should also be ready to adapt their learning style to flipped classroom.

The goal of the flipped classroom is the shift from passive learning to accelerated learning in order to foster learning at cognitively demanding levels such as analysis, synthesis and evaluation. Flipped classrooms are not a panacea for all of higher education teaching woes, they may offer several advantages over traditional didactic classroom environments. Thus, engaging millennial students through flipped classroom is challenging and we educators need to adapt and adopt it in changing times.

\section{Conflict of Interest}

None.

\section{References}

1. Hew K, Lo CK. Flipped classroom improves student learning in health professions education: a meta-analysis. BMC Med Educ. 2018;18(1):38.

2. Lockyer J, Ward R, Toews J. Twelve tips for effective short course design. Med Teach. 2005;27(5):392-5.

3. Wagner D, Laforge P, Cripps D. Lecture material retention: A first trial report on flipped classroom strategies in electronic systems engineering at the University of Regina. In: Conference Proceedings of the Canadian Engineering Education Association, Montreal, Canada; 2013.

4. Mcgivney-Burelle J, Xue F. Flipping calculus. Primus. 2013;23(5):477-86.

5. Giuliano CA, Moser LR. Evaluation of a flipped drug literature evaluation course. Am J Pharm Educ. 2016;80(4):66.

6. Cotta K, Shah S, Almgren MM, Macías-Moriarity LZ, Mody V. Effectiveness of flipped classroom instructional model in teaching pharmaceutical calculations. Curr Pharm Teach Learn. 2016;8(5):64653.

7. Galway LP, Corbett KK, Takaro TK, Tairyan K, Frank EA. Novel integration of online and flipped classroom instructional models in public health higher education. BMC Med Educ. 2014;14(1):181.

8. Vazquez JJ, Chiang EP. Flipping out! A case study on how to flip the principles of economics classroom. Int Adv Econ Res. 2015;21:379-90.

\section{Author biography}

Ajit Dabholkar, Professor and Head Sports Physiotherapy

Cite this article: Dabholkar A. Flipped classroom: Revisit, adapt and adopt. J Educ Technol Health Sci 2021;8(3):74-75. 